\title{
PERAN SUPERVISI KEPALA MADRASAH TERHADAP PELAKSANAAN TUGAS POKOK GURU PAI
}

\author{
RAUDLATUL MUNAWARAH \\ MAN 1 HSU, Prov. Kalimantan Selatan \\ E-Mail : warah711@gmail.com
}

\begin{abstract}
This study aims to reveal the report of the head of madrasah on the implementation of Islamic education teachers' duties in planning, implementing and the learning process. This study uses an Action Research Approach. The results showed that the supervision carried out by the head of madrasah could improve the implementation of the main duties of Islamic Education teachers. This also proves that the supervision of the head of madrasah and individual meetings with each PAI teacher to reflect on the learning process has a very important role in improving the implementation of the main tasks of Islamic Education teachers. The research implication is that if the role of supervision of the head of the madrasah is always carried out, the learning process in the classroom will provide good feedback between teachers and students.
\end{abstract}

Keyword : Supervision, Head Of School, Research Actions

\begin{abstract}
ABSTRAK
Penelitian ini bertujuan untuk mengungkapkan peranan supervisi kepala madrasah terhadap pelaksanaan tugas pokok guru PAI dalam merencanakan, melaksanakan dan mengevaluasi proses pembelajaran. Penelitian ini menggunakan Pendekatan Action Research. Hasil penelitian menunjukan bahwa supervisi yang dilaksanakan kepala madrasah dapat meningkatkan pelaksanaan tugas pokok guru PAI. Hal ini juga membuktikan bahwa supervisi kepala madrasah dan pertemuan individual dengan masing-masing guru PAI untuk merefleksi proses pembelajaran punya perananan yang sangat penting dalam meningkatkan pelaksanaan tugas pokok guru PAI. Implikasi penelitian ini jika peran supervisi kepala madrasah selalu dilaksanakan, maka proses pembelajaran di kelas akan memberi feedback yang baik antara guru dan siswa.
\end{abstract}

Kata Kunci : Supervisi, Kepala Madrasah, Penelitian Tindakan

\section{PENDAHULUAN}

Kepala madrasah adalah pemegang kunci keberhasilan keberlangsungan pendidikan di sekolah yang dipimpinya (Ekosiswoyo, 2016; Fitrah, 2017; Ramadoni, Kusmintardjo, \& Arifin, 2016). Sebagai orang yang punya peranan, kepala madrasah bertanggung jawab membantu, membimbing dan mengarahkan guru-guru yang mendapat kesulitan dalam pelaksanaan tugas. Kegiatan membantu memecahkan permasalahan yang dihadapi guru PAI tersebut dinamakan supervisi. Supervisi yang dilaksanakan kepala madrasah secara efektif dan berkelanjutan diharapkan akan memberikan kontribusi yang besar terhadap guru-guru PAI dalam usahanya memperbaiki dan meningkatkan cara kerja mereka dari waktu ke waktu (Ariana, Dantes, \& Lasmawan, 2015; Bogler \& Nir, 2015; Mette, Range, Anderson, Hvidston, \& Nieuwenhuizen, 2015).

Dalam bidang pendidikan Kepala madrasah dan guru merupakan komponen yang sangat penting dan memegang peranan. Keberhasilan pendidikan lebih banyak ditentukan oleh kemampuan guru dalam melaksanakan tugasnya (Ardi, 2017; Daharnis \& Ardi, 2016). Sebagai komponen penting dalam pendidikan di sekolah terdapat 5 tugas pokok yang harus dikerjakan oleh setiap guru, antara lain: (1) menjabarkan isi kurikulum, yaitu tugas guru dalam menyusun 
perencanaanpembelajaran, seperti menyusun program tahunan, semesteran, mingguan sampai ke program harian; (2) melaksanakan pembelajaran, yakni tugas guru menyampaikan tujuan dan materipembelajaran, dengan memilih metode, penggunaan alat/media dalam pembelajaran; (3) melaksanakan evaluasi/penilaian; (4) melaksanakan tugas dengan rasa tanggung jawab; (5) melaksanakan disiplin dalam arti luas (Ramadoni et al., 2016; Yunus, 2015).

Supervisi merupakan salah satu fungsi kepala madrasah untuk meningkatkan kualitas dan profesionalisme guru dalam melaksanakan pengajaran. Sehubungan dengan pentingnya aktifitas supervisi sekoalah yang berkaitan dengan peningkatan kualitas guru pada khususnya dan peningkatan mutu pendidikan pada umumnya. (Dedi Lazwardi,2016). Supervisi adalah usaha memberikan layanan kepada guru-guru baik secaraindividu maupun secara berkelompok dalam usaha memperbaiki pengajaran. Kata kunci dari pemberian supervisi pada akhirnya ialah memberikan layanan dan bantuan. (Sahertian, 2010).

\section{METODE PENELITIAN}

Penelitian ini menggunakan Penelitian Tindakan. Penelitian tindakan meliputi : (a) perencanaan tindakan berdasarkan kepada permasalahan yang dihadapi; (b) pelaksanaan tindakan; (c) pengamatan dan pengumpulan data; (d) analisis data hasil penelitian; (e) refleksi (perenungan) hasil analisis; (f) perubahan/revisi perencanaan untuk pengembangan selanjutnya. Penelitian ini terdiri dari 2 (dua) siklus. Setiap siklus dilakukan perencanaan tindakan, pelaksanaan/ observasi, analisis data dan refleksi. Subjek dalam Penelitian Tindakan Sekolah (PTS) ini adalah guru-guruPAI pada MAN 1 HSU yang berjumlah 9 orang, terdiri dari 2 orang guru Al Qur'an-Hadits, 2 orang guruFikih, 1 orang guru SKI, 2 orang guru Aqidah Akhlak.

Data yang dikumpulkan dalam penelitian ini adalah : (1) data tentang pelaksanaan tugas pokok guru dalam merencanakan pembelajaran; (2) datatentang pelaksanaan tugas guru dalam proses belajar mengajar; (3) data tentang pelaksanaan tugas guru dalammengevaluasi proses dan hasil pembelajaran. Dari ketiga sumber data di atas diperoleh data tentang pelaksanaan tugas pokok guru PAI.

Pengumpulan data dalam penelitian tindakan ini adalah dengan teknik wawancara, pengamatan ,dan angket denganmenggunakan alat pengumpul data berupa lembar pengamatan untuk mengamati pelaksanaan tugas pokok guru PAI dalam merencanakan pembelajaran digunakan lembar pengamatan terhadap RPP dan batas pelajaran. Agar dapat mengamati pelaksanaan pembelajaran digunakan lembar pengamatan terhadap pelaksanaan tugas guru PAI dalam kegiatan membuka dan menutup pembelajaran, penyampaian materi, penggunaan metode, alat/media pembelajaran. Sedangkan untuk mengamati pelaksanaan evaluasi pembelajaran digunakan lembar pengamatan terhadap analisis soal, analisis buku nilai, dan program tindak lanjut yang disusun guru.

Untuk menganalisis data digunakan teknik antara lain, data masing-masing indikator yang dianggap besar pengaruhnya terhadap pelaksanaan tugas pokok guru PAI. Pelaksanaan tugas pokok guru PAI diamati dan dianalisis berdasarkan fakta yang ada atau terlaksana. Indikator yang terlaksana diberi bobot nilai sesuai dengan kenyataan yang diamati. Hasil analisis kemudian dilakukan kategorisasi dengan menggunakan kriteria pada Tabel 1. 


\section{HASIL DAN PEMBAHASAN}

\section{Hasil}

Pelaksanaan tugas guru PAI dalam merencanakan pembelajaran akan dilihat dari Rencana Pelaksanaan Pembelajaran (RPP) yang telah disusun guru. Pelaksanaan tugas guru dalam proses pembelajaran akan dilihat dari kegiatan membuka, kegiatan inti, dan kegiatan menutup pembelajaran, penyampaian materi, penggunaan metode, alat/media pembelajaran. Data tentang pelaksanaan evaluasi pembelajaran akan diamati dari analisis soal, analisis buku nilai, dan program tindak lanjut yang disusun guru.

Tabel 1. Pelaksanaan Tugas Pokok Guru PAI pada Tindakan Siklus I

\begin{tabular}{lcccr}
\hline \multirow{2}{*}{\multicolumn{1}{c}{ Aspek Observasi }} & \multicolumn{3}{c}{ Karakteristik Guru } \\
\cline { 2 - 5 } & $\begin{array}{c}\text { Al Qur'an } \\
\text { Hadits }\end{array}$ & Fikih & SKI & $\begin{array}{r}\text { Aqidah } \\
\text { Akhlak }\end{array}$ \\
\hline Perencanaan Pembelajaran & & & & \\
RPP & 65 & 70 & 65 & 60 \\
Silabus & 68 & 70 & 65 & 65 \\
Buku Kurikulum 2013 & 70 & 70 & 70 & 70 \\
Batas Pelajaran & 68 & 65 & 65 & 69 \\
Alat/Media Pembelajaran & 60 & 60 & 70 & 65 \\
\hline Pelaksanaan Pembelajaran & & & & \\
Kegiatan membuka Pelajaran & 70 & 60 & 65 & 65 \\
Penyampaian Materi & 70 & 69 & 70 & 65 \\
Penggunaan Metode & 65 & 63 & 60 & 65 \\
Penggunaan Media/Alat Peraga & 60 & 60 & 70 & 70 \\
Kegiatan menutup Pembelajaran & 70 & 70 & 68 & 70 \\
\hline Evaluasi Pembelajaran & & & & \\
Analisis Butir Soal & 60 & 60 & 65 & 60 \\
Analisis Hasil Evaluasi & 65 & 65 & 65 & 60 \\
Refleksi Diri & 65 & 69 & 70 & 65 \\
Buku Nilai Program Tindak & 60 & 70 & 65 & 65 \\
Lanjut & & & & \\
\hline & & & & \\
Jumlah & 65,4 & 65,7 & 66,6 & 65,2 \\
\hline Kriteria & Baik & Baik & Baik & Baik \\
\hline
\end{tabular}




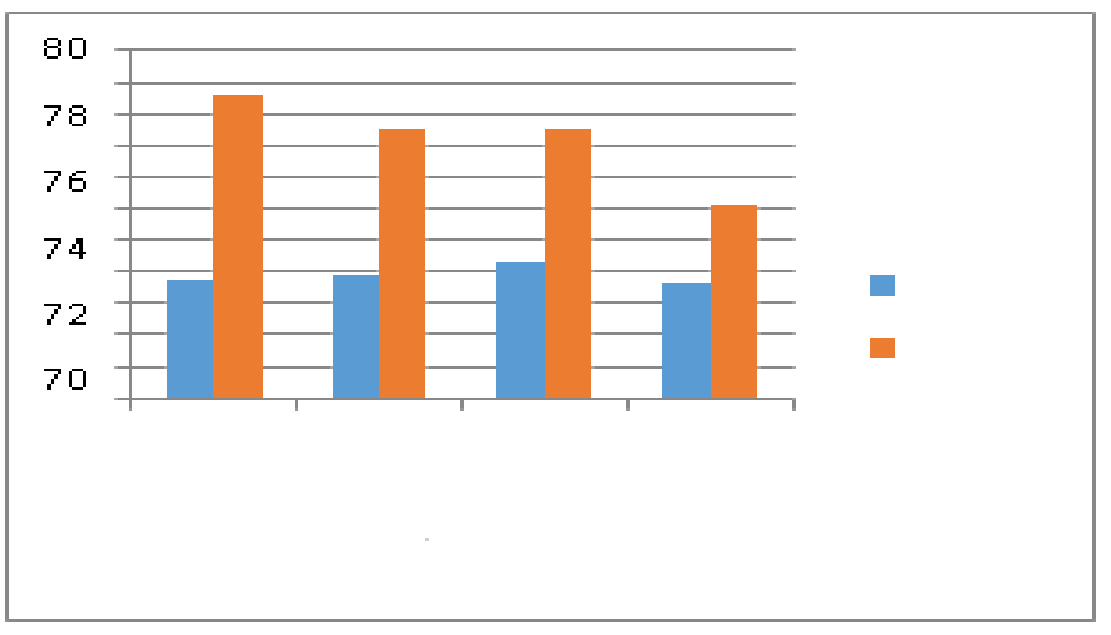

\section{Gambar 1. Pelaksanaan Tugas Pokok Guru PAI pada Tindakan Siklus I dan Sikulus II}

Berdasarkan data hasil pengamatan pada grafik di atas, terlihat bahwa semua guruPAitelah melaksanakan tugas pokoknya dengan baik. Semua guru PAI telah melakukan tahap perencanaan, pelaksanaan pembelajaran, dan evaluasi pembelajaran sesuai hasil refleksi dan berdiskusi dengan kepala madrasah beserta guru guru PAI terlihat aktif merancang pembelajaran terlihat aktif dan kreatif mengupayakan alat/media yang akan digunakan dalam proses pembelajaran. Semua guru guru PAI telah memperlihatkan usahanya melaksanakan evaluasi sesuai dengan ketentuan-ketentuan yang telah ditetapkan.

\section{Pembahasan}

Berdasarkan hasil pengamatan pada studi pendahuluan, menunjukkan bahwapelaksanaan tugas pokok guru guru PAI MAN 1 HSU, belum sepenuhnya terlaksana dengan baik. Terindikasi bahwa adanya beberapa guru PAI yang belum menyusun perencanaan pembelajaran, belum menggunakan alat/media dalam pembelajaran, belum menyusun program evaluasi pembelajaran yang dikerjakandengan baik.

Berdasarkan hasil pengamatan pada penelitian tindakan siklus pertama, diperoleh data bahwa telah ada peningkatan terhadap pelaksanaan tugas pokok guru PAI. Namun masih tergolong jauh dari harapan yang sesungguhnya. Agar pelaksanaan tugas pokok guru dapat terlaksana dengan baik,maka kepala madrasah mengadakan pertemuanindividual dengan masingmasing guru yang diamati untuk membicarakan pelaksanaan tugas pokok guru yang bersangkutan, memberi arahan dan petunjuk serta menyepakati untuk diadakan tindakan supervisi berikutnya.

Agar lebih maksimalnya hasil pembinaan/supervisi kepala madrasah ini, maka diadakan kegiatan demonstrasi mengajar oleh kepala madrasah. Untukmembantu pelaksanaan tugas guru PAI, kepala madrasah perlu menunjukkan bagaimana cara mengajar yang baik dan sesuai dengan tahapan perkembangan siswa. Setelah kegiatan pada siklus I selesai, diadakan diskusi mengenai demonstrasi mengajar yang dipertunjukkan kepala madrasah. Perbaikan dan penguatan yang disepakati pada diskusi tersebut menjadi catatan pada pelaksanaan supervisi berikutnya.

Temuan lainnya dari penelitian ini masih diperlukan adanya perbaikan mengenai kemampuan guru dalam menyusun soal-soal yang berbasis High Order Thinking Skill,a meggunakan metode pembelajaran yang relevan untuk meningkatkan sikap saintifik pada diri siswa. Serta terlihat siswa masih merasa kurang percaya diri dalammengeksplorasi lingkungan di sekitarnya. 
Berdasarkan hasil pengamatan pada penelitian tindakan siklus kedua, hasil supervisi yang dilaksanakan kepala madrasah dapat meningkatkan pelaksanaan tugaspokok guru PAI. Hal ini membuktikan bahwa supervisi kepala madrasah dan pertemuan individual dengan masingmasing guru untuk merefleksi proses pembelajaran punya peranan yang sangat penting dalam meningkatkan pelaksanaan tugas pokok guru PAI.

Hal ini diperkuat oleh hasil penelitian yang menyatakan terdapat pengaruh positif supervisi kepala madrasah dan motivasi kerja guru terhadap kinerja guru (Uli : 2012). Penelitian lainnya juga dibuktikan oleh Hadis(2005) yang menunjukkan, bahwa terdapat kontribusi antara supervisi kepala madrasah dan profesionalisme guru, serta mutu proses dan hasil belajar peserta didik terhadap mutu pembelajaran ialah signifikan dan tingkat korelasinya adalah sedang, yaitu 0,460 .

\section{KESIMPULAN}

Hasil penelitian membuktikan bahwa dengan dilaksanakan supervisi kepala madrasah, dapat meningkatkan pelaksanaan tugas pokok guru. Semua guru telah mempunyai tanggung jawab terhadap perencaan pembelajaran, transfer of knowledge kepada siswa, hingga menyusun evaluasi proses pembelajaran. Proses pembelajaran akan berjalan dengan baik jika ada feedback antara guru dan siswa.

\section{DAFTAR PUSTAKA}

Ardi, Z., \& Erlamsyah, E. (2017). Peningkatan Kualitas Penulisan Artikel Ilmiah bagi Kepala madrasah. Jurnal Aplikasi IPTEK Indonesia, 1(1), 25-34.

Ariana, I. W., Dantes, N., \& Lasmawan, I. W. (2015). Kontribusi supervisi kepala madrasah, motivasi berprestasi dan komitmen kerja terhadap kinerja guru di gugus sekolah VIII KecamatanAbang. PENDASI: Jurnal Pendidikan Dasar Indonesia, 5(1).

Bogler, R., \& Nir, A. E. (2015). The contribution of perceived fit between job demands and abilities to teachers' commitment and job satisfaction.Educational Management Administration \& Leadership, 43(4),541- 560.

Daharnis, D., \& Ardi, Z. (2016). The Compatibility Student Choice of University Majoring; A Preliminary Studies. GUIDENA: Jurnal Ilmu Pendidikan, Psikologi, Bimbingan Dan Konseling, 6(1), 101-109.

Dedi Lazward, Implementasi Supervisi Pendidikan Di Sekolah/Madrasah. Jurnal Kependidikan Islam. Doi: Http://Dx.Doi.Org/10.24042/Alidarah.V6i1.794

Ekosiswoyo, R. (2016). Kepemimpinan kepala madrasah yang efektif kunci pencapaian kualitas pendidikan. Jurnal Ilmu Pendidikan, 14(2).

Hadis, A. 2005. Kontribusi Supervisi Kepala madrasah, Guru terhadap Mutu Proses dan Hasil Belajar Siswa di SMAN Kota Bandung. Jurnal Mimbar Pendidikan. No. 2/XXIV/ 2005. H. 40-46

Mette, I. M., Range, B. G., Anderson, J., Hvidston, D. J., \& Nieuwenhuizen, L. (2015). Teachers' Perceptions of Teacher Supervision and Evaluation: A Reflection of School Improvement Practices in the Age of Reform. Education Leadership Review, 16-30.

Ramadoni, W., Kusmintardjo, K., \& Arifin, I. (2016). Kepemimpinan Kepala Sekolah dalam Upaya Peningkatan Kinerja Guru (Studi Multi Kasus di Paud Islam Sabilillah dan Sdn Tanjungsari 1 Kabupaten Sidoarjo). Jurnal Pendidikan: Teori, Penelitian, Dan Pengembangan, 1(8), 1500-1504.

Sahertian, Piet A. (2010). Teknik Supervisi Pendidikan. Jakarta: Rineka Cipta.

Uli Uslihatul Auliya, Partono Thomas, Lyna Latifah. (2012). Pengaruh Supervisi Kepala madrasah Dan Motivasi Kerja Guru Terhadap Kinerja Guru. Economic Education Analysis Journal. 